In this case gonorrhoea could be negatived by the complete absence of any purulent discharge and the slight and transient nature of the conjunctivitis.

No history of haemophilia could be obtained from either parent, nor had they any knowledge of its occurrence in their respective families.

\title{
ANNOTATIONS
}

\section{A Great Neurological Triad}

The publication of Sherrington's lectures on "The Integrative Action of the Central Nervous System" in the year 1906 was one of the most important milestones on the road of neurological research. In that volume was codified, for the first time, all the researches which Sherrington and his pupils had been carrying on over a long series of years. The characteristics of the spinal reflex were defined and we were allowed to see, as in a glass darkly, something of the working of the central nervous system. It would be impossible within the limits of a short annotation to enumerate all the various lines of research which have been inspired by Sherrington's great work, but, for two reasons, the present would seem to be a suitable time to refer to two of the greatest branches which have grown from the tree which he then planted. The first can only be referred to with deep regret. The recent death of Professor Magnus of Utrecht has been a very grievous loss to physiology. One of the most brilliant of Sherrington's disciples, he was the inspiration of the Dutch school of neurological research, and his recent book "Körperstellung" does for the mid-brain region what Sherrington's work had already done for the spinal cord. It has established itself as one of the classics of neurology, worthy to take its place beside "The Integrative Action of the Central Nervous System."

The second of the great branches which has sprung from this common stem is Pavlov's work on "Conditioned Reflexes." What Sherrington did for the spinal cord and Magnus for the mid-brain, Pavlov has essayed to do for the cortex cerebri. Hitherto, in England, we have only known somewhat vaguely of the work done by the distinguished Petrograd physiologist on these lines. Most of the papers have been in a language not readily available to the ordinary Englishman. With the assistance of a grant from the Royal Society, Dr. Anrep has now published a translation of Pavlov's lectures in which are summarized the researches which he and his pupils have been carrying on for the 
last twenty-five years. This book "Conditioned Reflexes" will be to many a revelation of a new country. After the loose talk and looser thinking which characterizes much of the socalled "psychology" of the present day, it is as refreshing as getting out into the fresh air after being in the fuggy miasma of a tropical jungle. Here we have no cloud-soaring superstructure of argument based on unverified and often incredible assumptions, but simple plain statements of measured actions and reactions, and deductions therefrom. If psychology is ever to become a science Pavlov has shown how it may come about. It is not easy reading; the country is new and the paths are not well-trodden, but Pavlov's book takes its place with those of Sherrington and Magnus in forming what we have called "a great neurological triad." The knowledge contained in these three great works will give the student of the future a sure foundation on which to build up a true science of psychology.

Though mainly neurological in their interest there is much of value to the ophthalmologist, especially in the work of Magnus on ocular reflexes controlled by the labyrinth and the conditioned reflexes of Pavlov resulting from visual stimuli.

\section{Monograph Supplements and Books}

This journal, as our readers are aware, has on three occasions distributed to its subscribers valuable monographs which it would have been impossible, on account of their size, to publish in an ordinary issue. These three : "Parenchymatous Keratitis," by Holmes Spicer ; "Retinal Venous Thrombosis," by R. Foster Moore; "Biochemistry of the Aqueous humour," by W. S. DukeElder, have, we know, been much appreciated.

Early in the New Year the journal embarks on a new venture, the publication of "The Development of the Human Eye," by Miss Ida Mann. The printing and publishing will be in the hands of the Cambridge University Press. It is not our place to praise our own children before they see the light, but those of us who have had the privilege of seeing the manuscript are convinced of its value. Miss Mann has already shown her capacity for the work in several papers and exhibits. Further, there is no book in the English language in which the known facts of ocular development are specially dealt with. Bach and Seefelder (in German) appeared before the war and Versari's valuable contributions to the subject (in Italian) have never been collected into one volume from the various journals in which they appeared. The value of such a book is not confined to the theoretical questions involved, important as these should be to all ophthalmologists. The work has a very practical value in the 